\title{
Relationships between autumn precipitation anomalies in southeastern South America and EI Niño event classification
}

\author{
P. L. Antico* \\ Departamento de Ciencias de la Atmósfera y los Océanos, Facultad de Ciencias Exactas y Naturales, Universidad de Buenos Aires, Consejo \\ Nacional de Investigaciones Científicas y Técnicas, Argentina
}

\begin{abstract}
The classification of El Niño events was performed based on the time evolution of sea surface warming in the tropical Pacific Ocean during the period 1950-2000. Two sets of events were constructed: one in which the warming core migrates eastward along the tropical Pacific until April-June of the following year, and another one in which it evolves westward until November-January. The first type has associated positive precipitation anomalies over southeastern South America during April-June. It results from a favourable combination of cyclonic vorticity advection and humidity convergence. At high levels, cyclonic vorticity advection is explained in terms of an eastward extension of the subtropical jet. Enhanced humidity advection takes place by an increased low-level northwesterly flow to the east of the Andes. It provides enough moisture availability that, in combination with the upper-level cyclonic vorticity advection, supports heavy precipitation during April-June. The second type of event exhibits slight negative or near-normal precipitation anomalies over the same region. Both low and high-level circulation anomalies are also weaker in this case. The 1997-1998 El Niño is analysed separately because it cannot be classified into any of the previously described event types.

The observed distribution of both types of events along the analysed period changes after the 1970s. Comparison with other authors' results suggests the influence of low-frequency processes such as the Pacific Decadal Oscillation (PDO). Copyright (C) 2008 Royal Meteorological Society
\end{abstract}

KEY WORDS South America; precipitation; El Niño; tropical Pacific Ocean

Received 13 September 2007; Revised 13 May 2008; Accepted 17 May 2008

\section{Introduction}

It is known that the El Niño Southern Oscillation (ENSO) has a strong influence on interannual rainfall variability over southeastern South America (e.g. Ropelewski and Halpert, 1987; Aceituno, 1988; Diaz et al., 1998; Grimm et al., 1998; Grimm et al., 2000; Barros and Silvestri, 2002). In particular, ENSO has a considerable impact on the discharge of the main rivers in the Plata basin, i.e. the Paraná, the Paraguay and the Uruguay rivers (Berri et al., 2002; Camilloni and Barros, 2003; Barros et al., 2004). In the case of the Parana river, five out of the six major discharges in the twentieth century occurred during the autumn following the year of the El Niño onset (Camilloni and Barros, 2003), hereinafter referred to as autumn(+). Similarly, in the Paraguay river, six out of the nine greatest discharges occurred simultaneously with El Niño events, and five of them during autumn $(+)$ (Barros et al., 2004). Thus, ENSO impacts on river discharge are more noticeable during autumn at the end of the event.

\footnotetext{
* Correspondence to: P. L. Antico, Departamento de Ciencias de la Atmósfera y los Océanos, Facultad de Ciencias Exactas y Naturales, Universidad de Buenos Aires, Pabellón 2 Piso 2, Ciudad Universitaria, Buenos Aires, Argentina. E-mail: antico@at.fcen.uba.ar
}

The first conceptual models of El Niño (Rasmusson and Carpenter, 1982) described the phenomenon as equatorial positive sea surface temperature anomalies migrating westward from the American coast to the central Pacific. Later, Wang (1995), and Wang and Ropelewski (1995) identified other El Niño events with warm anomalies migrating eastward in the tropical Pacific.

This study relates the occurrence of precipitation anomalies in southeastern South America during autumn with distinctive developments of El Niño events. The latter are classified in terms of differences in the time series of sea surface temperature indices in the tropical Pacific Ocean. Then, two types of El Niño events are defined. Anomalous field composites were computed for each type of event to capture the main circulation and precipitation anomalies. The description of datasets and methodology is presented in Section 2. Section 3 discusses anomaly composites for several variables within the corresponding subsections. Precipitation is analysed in Section 4. Then the special case of El Niño 1997-1998 is analysed in Section 5. Finally, the summary and conclusions are presented in Section 6.

\section{Data and methodology}

Sea surface temperatures were obtained from the National Oceanic and Atmospheric Administration (NOAA), 
Extended Reconstructed Sea Surface Temperature (ERSSTv2) monthly dataset with a spatial resolution of $2^{\circ} \times 2^{\circ}$ for the period 1950-2000 (Smith and Reynolds, 2004). National Centers for Environmental Prediction (NCEP) reanalysis monthly data were used for the same period with $2.5^{\circ} \times 2.5^{\circ}$ horizontal resolution (Kalnay et al., 1996). Reanalyses are available at the website of NOAA-CIRES Climate Diagnostics Center, Boulder, Colorado, USA, http://www.cdc.noaa.gov/. Precipitation analysis corresponds to the monthly global dataset prepared by the University of Delaware at $0.5^{\circ} \times 0.5^{\circ}$ resolution (Legates and Willmott, 1990).

Following the definition of El Niño periods given by Trenberth (1997), the time series of the Niño 3.4 index, monthly anomalies were computed considering the base period 1950-2000. Though different from Trenberth's (1997), the base period was defined to capture the interdecadal variability of sea surface temperature in the Pacific Ocean. An El Niño event is defined when the 5month moving average of the index anomaly is greater than or equal to $0.4^{\circ} \mathrm{C}$ for at least 6 months. During the period 1950-2000, 15 El Niño events were identified (Figure 1). Despite the differences in the base period and the database, the list of events almost coincides with that in Trenberth (1997). The only exception is the El Niño 1979-1980, which does not meet the definition criteria.

From now on, we will use the term 'phase' to refer to the difference, expressed in months, between the occurrence of peaks in the 3-month-centred moving averages of the anomalies of the Niño 3.4 and the Niño $1+2$ indices. A phase is defined as positive (DF+) when the maximum anomaly in the Niño 3.4 index occurs before the maximum in the Niño $1+2$. In these cases, the latter occurs during March-June following the year of the El Niño onset. On the other hand, the phase is defined as negative (DF-) when the maximum anomaly in the Niño 3.4 index occurs after the maximum in the Niño $1+2$, which occurs during April-July.

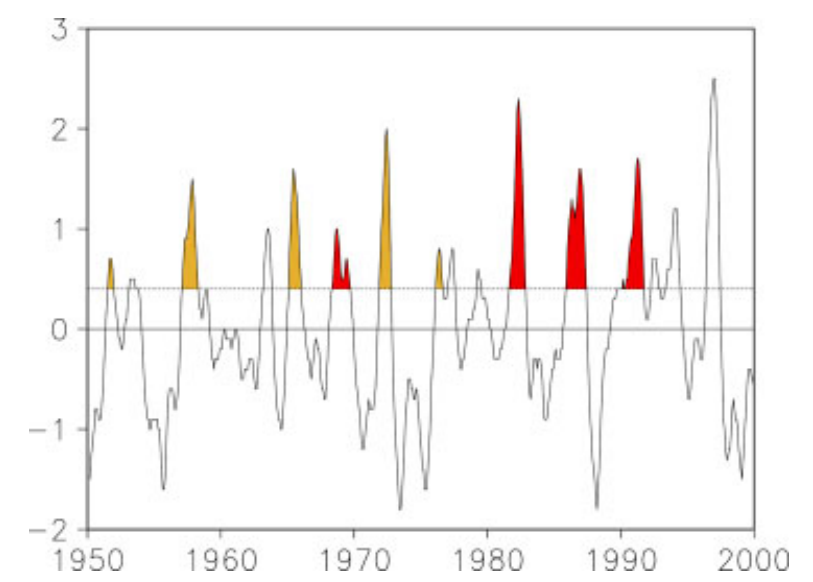

Figure 1. Time series plot of 5-month moving average of the Niño 3.4 sea surface temperature index anomalies as departures from the 1950-2000 base period. A threshold of $0.4{ }^{\circ} \mathrm{C}$ is indicated with a dashed line to define El Niño events. Dark (light) shading indicates $\mathrm{DF}+(\mathrm{DF}-)$ events. This figure is available in colour online at www.interscience.wiley.com/ijoc
Thus, a set with four DF+ events and another set with five DF- events were identified during the period 1950-2000, as is shown in Figure 1 and listed in Table I. These sets are used to compute the corresponding composite means.

\section{Analysis of anomaly composites}

Time series of the Niño 3.4 and Niño $1+2$ for each individual event are shown in Figure 2(a)-(d) with their corresponding averages for the $\mathrm{DF}+$ and $\mathrm{DF}-$ events. The averaged anomaly peak in the Niño 3.4 index occurs in January $(+)$ for the DF+ events (Figure 2(a)) and in December (0) for the DF- events (Figure 2(b)). On the other hand, the averaged anomaly peak in the Niño $1+2$ occurs in $\mathrm{May}(+)$ for the $\mathrm{DF}+$ events (Figure 2(c)) and in July(0) during the DF- events (Figure 2(d)). In order to capture all the peaks from individual events, the following 3-month periods were constructed: $\operatorname{May}(0)-J u l y(0)$, November(0)-January $(+)$ and April(+)-June(+). Later on, these will be referred to as $\operatorname{MJJ}(0), \operatorname{NDJ}(0)$ and $\operatorname{AMJ}(+)$, respectively. Since the averaged Niño 3.4 anomalous index peaks during $\operatorname{NDJ}(0)$ for both types of El Niño events, the major differences in the anomaly time series will occur for the Niño $1+2$ index during $\operatorname{MJJ}(0)$ and $\operatorname{AMJ}(+)$. In the case of DF+ events, the comparison of Figure 2(a) and (c) clearly shows the eastward migration of the anomalies peak from the central tropical Pacific (Niño 3.4 index) during $\mathrm{NDJ}(0)$ towards the far eastern tropical Pacific (Niño $1+2$ index) during $\operatorname{AMJ}(+)$. Conversely, westward migration of the anomaly peak occurs during DF- events from the South American coast at the far eastern Pacific to the central Pacific is evident when comparing Figure 2(c) and (d).

It may be seen in Figure 1 that there are a number of El Niño events that are not classified either as DF+ or DFevents. These are the 1953, 1963-1964, 1977-1978, 1993, 1994-1995 and 1997-1998 events. The anomaly series of their Niño3.4 and Niño $1+2$ indices are shown in Figure 2(e) and (f) with the corresponding averages, excluding 1997-1998 to avoid bias. Except those of 1953 and 1993, all of them have their peaks in the anomalous Niño 3.4 and Niño $1+2$ index series during September-January. This feature may lead to a definition of a third type of event, i.e. those events having almost

Table I. Sets of El Niño events classified as DF+ or DFduring the period 1950-2000. Events are identified by the beginning and ending years.

\begin{tabular}{lc}
\hline DF + events & DF- events \\
\hline $1968-1969$ & $1951-1952$ \\
$1982-1983$ & $1957-1958$ \\
$1986-1987$ & $1965-1966$ \\
$1991-1992$ & $1972-1973$ \\
& $1976-1977$ \\
\hline
\end{tabular}



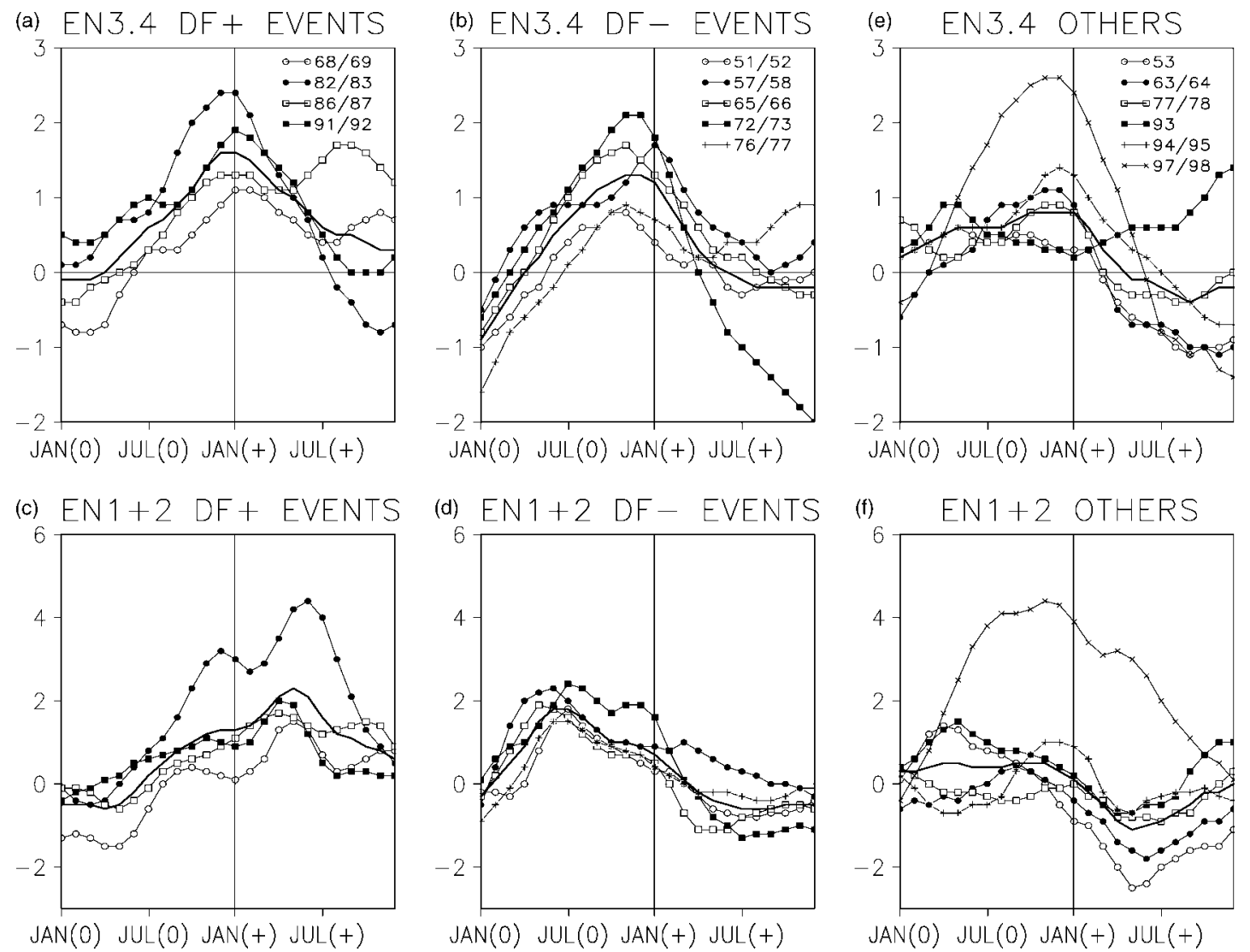

Figure 2. Time series plots of 3-month moving average of the Niño 3.4 (upper panels) and the Niño $1+2$ (lower panels) sea surface temperature indices for each individual El Niño events classified as DF+ (left), DF- (middle) and others (right) during the period 1950-2000. The symbol 0 at the horizontal axis indicates months of the El Niño onset year; the symbol + indicates months of the following year. Values are anomalies in $^{\circ} \mathrm{C}$ relative to the 1950-2000 base period. The heavy solid line is the mean time series for each sea surface temperature index and different types of events, excluding 1997-1998 in (e)-(f) panels.

a simultaneous warming along the central and eastern tropical Pacific. However, most of them depend to some extent on previous El Niño events. For instance, the 1977-1978 and 1993 events are actually a continuation of warm conditions after the 1976-1977 and 1991-1992 El Niño events, respectively (Figure 1). The same occurs with the 1994-1995 event and the previous 1993 event. In the case of El Niño 1997-1998, even though it is not related to a previous event, its unprecedented high sea surface temperature anomalies (Figures 1 and 2(e), (f)) lead to a particular anomaly pattern during $\mathrm{AMJ}(+)$, including precipitation anomalies, that resemble in many aspects those of the DF+ events. This will be further discussed in Section 5. In particular, the 1953 event is not considered because it is very weak and completely out of phase compared with other events. Finally, the 1963-1964 event is not preceded by an El Niño event, as in the previous case of 1997-1998. It has no remarkable features that may be related with any of the other types of events, hence it is not considered in this study.

\subsection{Sea surface temperature}

The distribution of sea surface temperature anomalies over the Pacific during $\mathrm{MJJ}(0)$ for each type of event is shown in Figure 3(a) and (b). In the same figure, the statistical significance given by the Student's $t$-test is also shown. Even though both types of events have an anomalous warming in the tropical Pacific, sea surface temperature anomalies seem to favour the further development of positive anomalies in the central tropical Pacific only during the DF+ events.

During NDJ(0), DF+ events (Figure 3(c)) show the highest statistical significance on positive anomalies to the west compared to that of the DF- events (Figure 3(d)) on the central tropical Pacific. Accordingly, the negative anomaly over New Zealand acquires higher statistical significance during DF- events, as well as the anomalous warming centred at $35^{\circ} \mathrm{S} 150^{\circ} \mathrm{W}$. On the other hand, during $\mathrm{DF}+$ events positive anomalies extend to the southeast over the eastern tropical South Pacific. Another difference is that the sea surface cooling observed over the North Pacific is enhanced during the DF+ events.

Major differences between $\mathrm{DF}+$ and $\mathrm{DF}-$ sea surface temperature patterns occur during $\mathrm{AMJ}(+)$ (Figure 3(e) and (f)). During this period, the anomaly pattern for DFevents does not evidence remarkable features. However, $\mathrm{DF}+$ events reveal an anomalous pattern quite similar to the $\operatorname{NDJ}(0)$ pattern, with the highest warming shifted eastward. In addition, negative anomalies deepen over the North Pacific and New Zealand during DF+ events, whereas positive anomalies are also enhanced over the central South Pacific. 

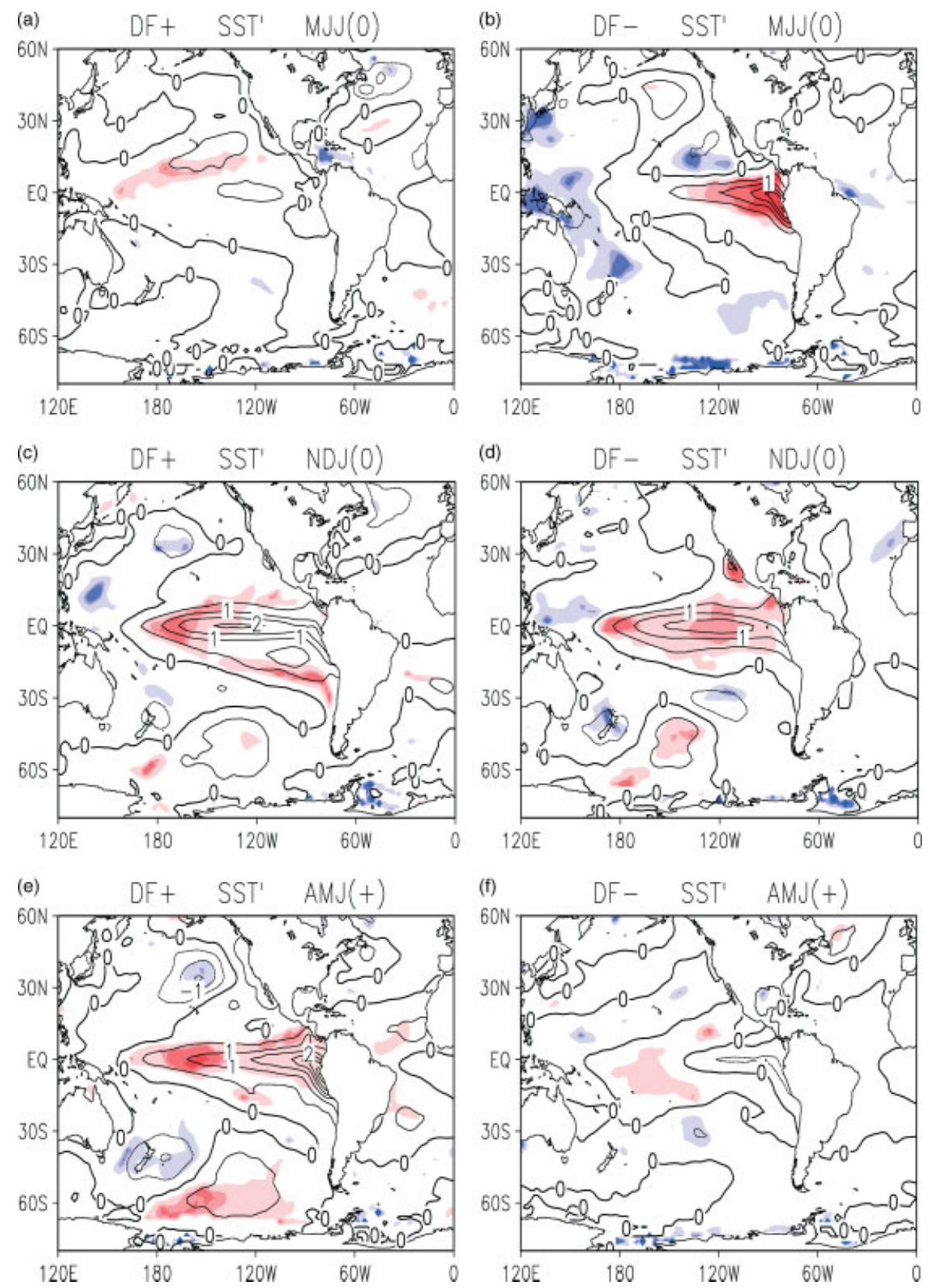

Figure 3. Mean sea surface temperature anomalies for El Niño events classified as DF+ (left panels) and DF- (right panels) as the 3-month average May-July (a) and (b) during the El Niño year; November-January (c) and (d) during the El Niño peak; and April-June (e) and (f) during the year following the El Niño onset. Anomalies are relative to the $1950-2000$ base period. Contour interval is $1{ }^{\circ} \mathrm{C}$. Dashed contours indicate negative anomalies. Shading in red (blue) indicates positive (negative) anomalies at the 95\% confidence level according to Student's $t$-test; darker shading at the $99,99.5$ and $99.9 \%$ level.

The persistence of the negative anomaly in the North Pacific between $\mathrm{NDJ}(0)$ and $\mathrm{AMJ}(+)$ during $\mathrm{DF}+$ events resembles the warm phase of the Pacific Decadal Oscillation (PDO) pattern (Mantua et al., 1997). As shown in Table I most of DF+ events occur after the 1970s, when $\mathrm{DF}-$ events did not occur. It is exactly during this decade when the PDO changes its phase from negative (cold) to positive (warm) conditions.

\subsection{High-level circulation}

Anomalies of stream-function at the 0.21 sigma level, which approximately correspond to the 200-hPa level, were chosen as representative of the upper tropospheric circulation (Figure 4(a)-(f)). The Rossby-like response in the tropical high-level circulation in the presence of positive sea surface temperature anomalies during El Niño events appears as a pair of anticyclonic anomalies centred off the equator. Their position is affected by the spatial distribution of sea surface temperature anomalies over the tropical region in each type of event. Whereas high-level circulation anomalies do not show relevant features over the Pacific Ocean during the onset of $\mathrm{DF}+$ events, i.e. during MJJ(0) (Figure 4(a)), a pair of anticyclonic anomalies straddles the equator from $160^{\circ} \mathrm{E}$ to $150^{\circ} \mathrm{W}$ over the tropical Pacific during the $\mathrm{DF}-$ events (Figure 4(b)). However, the area affected with positive 

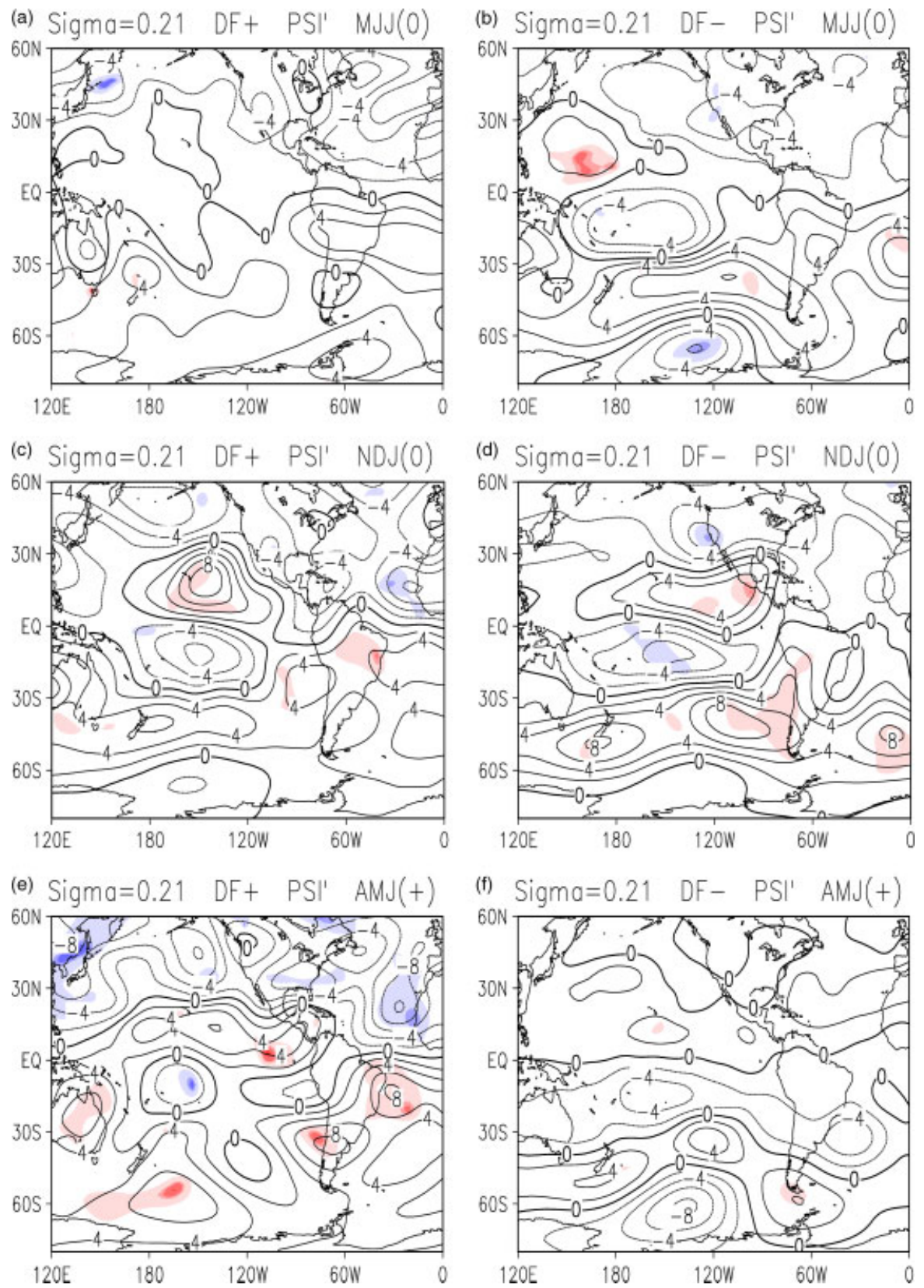

Figure 4. As in Figure 3 with stream-function anomalies at the 0.21 sigma level instead of sea surface temperature. Contour interval is $2 \times 10^{6} \mathrm{~m}^{2} \mathrm{~s}^{-1}$. This figure is available in colour online at www.interscience.wiley.com/ijoc

sea surface temperature anomalies extends to the east of the date line (Figure 3(b)). Hence, the more significant anticyclonic pair at $160^{\circ} \mathrm{E}$ does not necessarily result from the anomalous sea surface warming in the tropical Pacific, as it should be the case to the east of the date line. The relationship between circulation anomalies and sea surface temperature is more evident during $\mathrm{NDJ}(0)$, when comparing Figures 3(c), (d) and 4(c), (d) While during $\mathrm{DF}+$ events (Figure 4(c)) the anticyclonic pair is well defined and centred at $140^{\circ} \mathrm{W}$, during the DF- events (Figure 4(d)) they are zonally elongated affecting also the eastern tropical Pacific due to the eastward displacement of the positive sea surface temperature anomalies. The persistence of positive sea surface temperatures over the eastern Pacific during $\mathrm{AMJ}(+)$ for the $\mathrm{DF}+$ events
(Figure 4(e)) supports the anticyclonic pair well extended over the South American coast. Also remarkable is the pair of cyclonic anomalies centred off the equator on the Atlantic. The quadrupole pattern formed by the anticyclonic pair on the Pacific and the cyclonic one on the Atlantic may also be a Rossby-like atmospheric response to El Niño conditions during $\operatorname{AMJ}(+)$. At subtropical latitudes there is a cyclonic anomaly zonally elongated along $35^{\circ} \mathrm{S}$ over South America. Its major statistical significance is found off the American coast. Together with the Pacific anomalous anticyclone, it supports the strengthening and eastward extension of the subtropical jet stream over the continent. These anomalous patterns of the jet stream have been associated to higher than normal precipitation in southeastern South 
America during winter(0) (Antico, 2003) and spring(0) (Ropelewski and Halpert, 1987). Consistently with the sea-surface temperature anomalies for $\mathrm{DF}$ - events during $\mathrm{AMJ}(+)$ (Figure 3(f)), high-level circulation anomalies do not show relevant features over the tropical Pacific.

\subsection{Low-level circulation and humidity advection} during $\mathrm{AMJ}(+)$

Low-level circulation for DF+ and DF- events was represented by the $850-\mathrm{hPa}$ wind field. The corresponding mean and anomalous composites are shown in Figure 5(a)-(d), together with the wind vectors and the advection of specific humidity. The climatological April-June mean circulation is apparent in both types of events (Figure 5(a) and (b)). Between the equator and $15^{\circ} \mathrm{S}$, circulation is dominated by the easterlies. Negative humidity advection occurs along the northeastern South American coast. Poleward of $30^{\circ} \mathrm{S}$, the westerlies become the dominant circulation feature. At subtropical latitudes, the eastern slope of the Andes acts as an obstacle for the low-level flow, which follows a southward path from 15 to $30^{\circ} \mathrm{S}$. This meridional flow defines the western edge of the Atlantic anticyclone, in opposition to the northward flow related to the Pacific anticyclone west of the Andes. Consequently, positive humidity advection occurs over most of subtropical South America to the east of the Andes. This advection is enhanced during DF+ events mainly due to an increase in the northwesterly flow along the eastern slope of the Andes, as it is shown in Figure 5(c). There is also an anomalous southward humidity advection along the subtropical Atlantic coast. Along the equator, easterly anomalies are found from the Atlantic to the Andes mountains. Together with the anomalous northerly wind over the Atlantic these features may result in a westward shift of the Atlantic anticyclone.

On the other hand, during DF- events (Figure 5(d)) humidity advection does not exhibit major anomalies for $\operatorname{AMJ}(+)$. However, low-level circulation anomalies show a strengthening in northerly flow along $53^{\circ} \mathrm{W}$ from 10 to $30^{\circ} \mathrm{S}$.

\section{Precipitation over southeastern South America}

During MJJ(0), both types of El Niño events have weak precipitation anomalies in southeastern South America (not shown). However, as the El Niño events develop during $\mathrm{NDJ}(0)$ precipitation anomalies acquire statistical significance during DF+ and DF- events (Figure 6(a) and (b)). Even though both composites have positive precipitation anomalies over southeastern South America, they look different for each type of event. Positive anomalies occur during DF+ events (Figure 6(a)), between 35 and $15^{\circ} \mathrm{S}$ over Paraguay, southern Brazil, northeastern Argentina and north of Uruguay. Negative anomalies affect the northwestern portion of the domain, to the north of $15^{\circ} \mathrm{S}$. During DF- events (Figure 6(b)) positive precipitation anomalies also occur, extending southward over central Argentina and Uruguay, where they become statistically significant. There is also a region with positive precipitation anomalies to the northeast of Paraguay surrounded by negative precipitation anomalies. To the north of this area, precipitation anomalies are mostly negative.
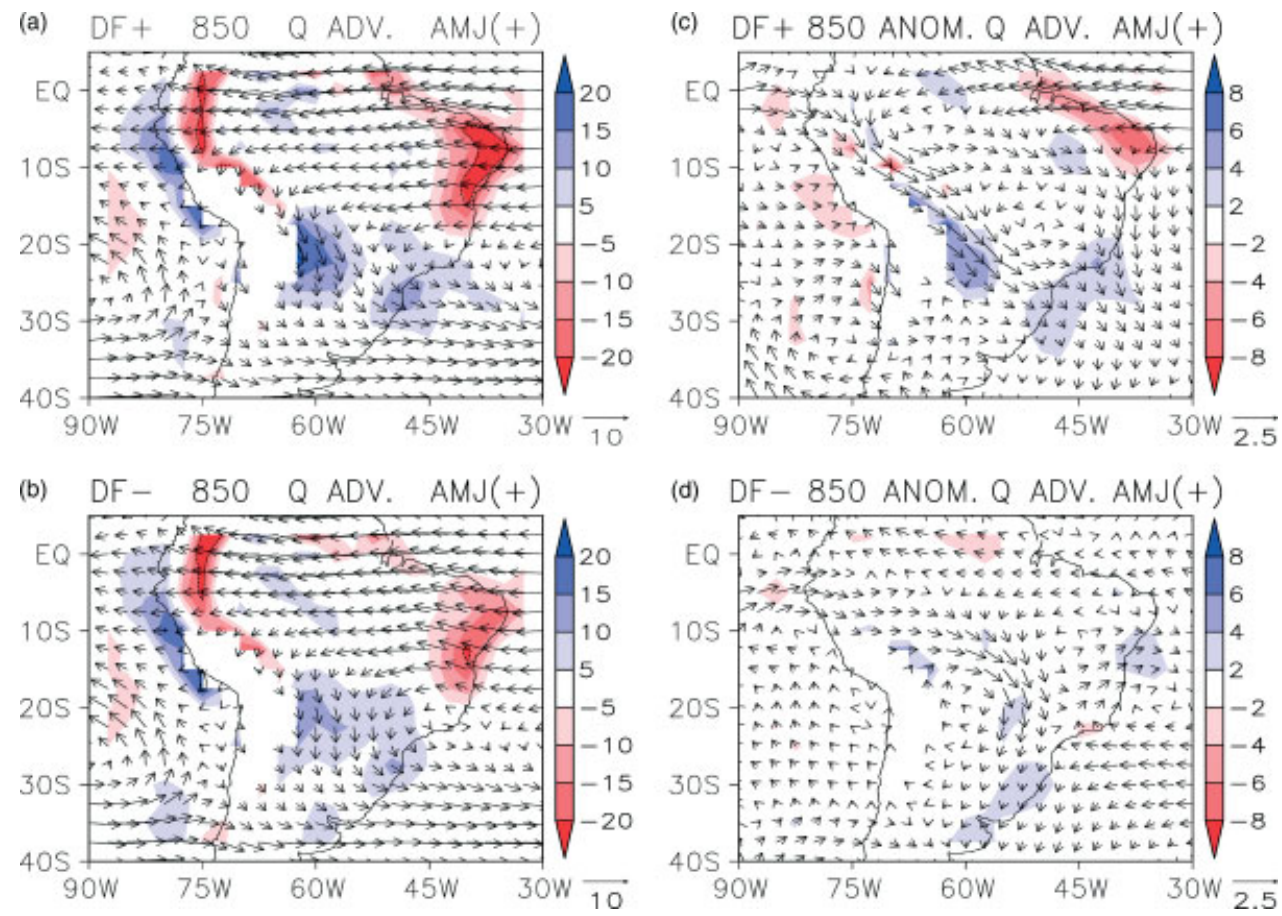

Figure 5. Mean wind and specific humidity advection (left panels) and anomaly (right panels) at the 850-hPa level during April-June following the El Niño onset for DF+ events (a) and (c) and DF- events (b) and (d). Shading in blue (red) indicates positive (negative) humidity advection. Solid (dashed) contour indicate values greater (less) than $\pm 20 \times 10^{-3} \mathrm{~g} \mathrm{~kg}^{-1} \mathrm{~s}^{-1}$. Reference vector for mean and anomalous wind is 10 and $2.5 \mathrm{~m} \mathrm{~s}^{-1}$. This figure is available in colour online at www.interscience.wiley.com/ijoc 

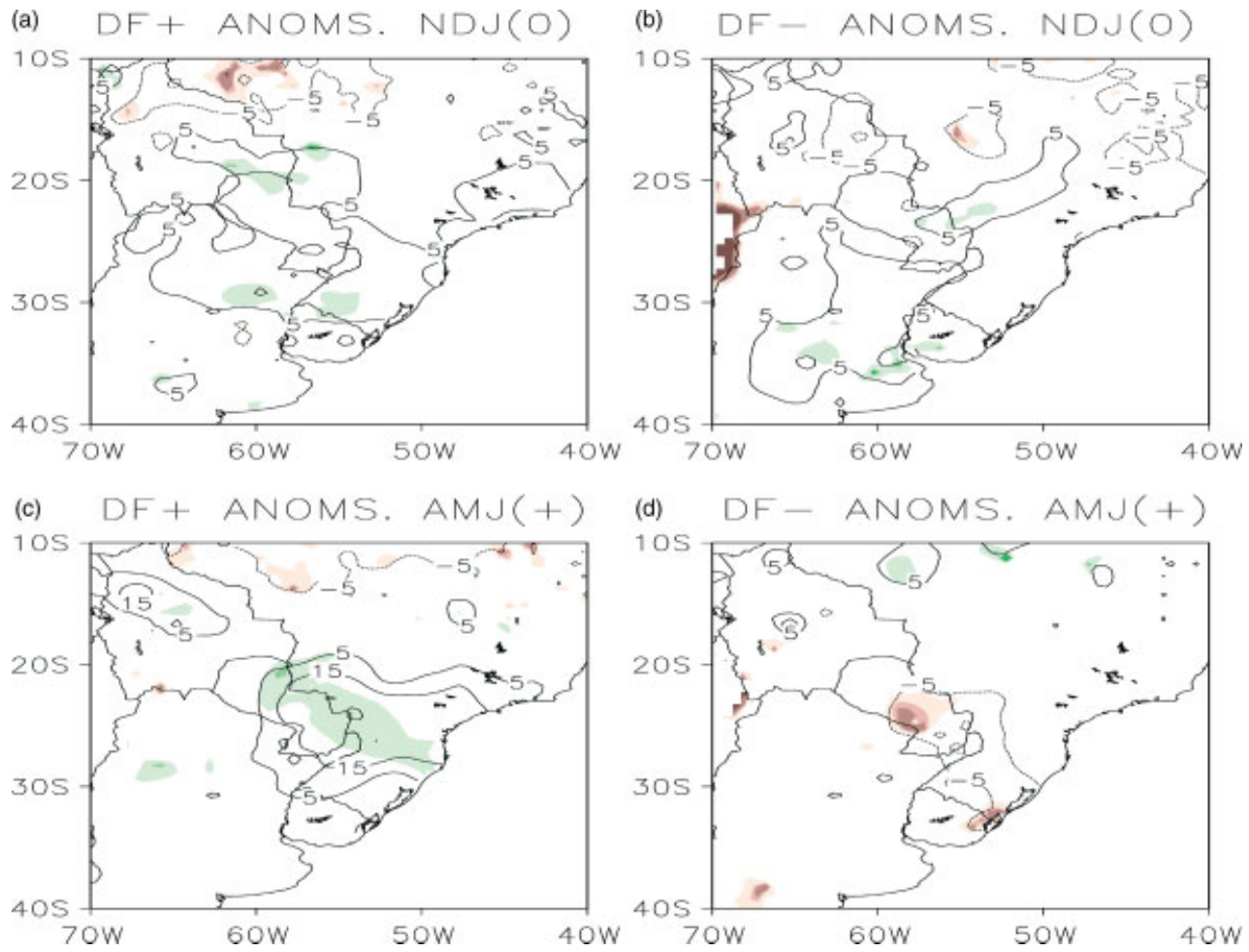

Figure 6. Mean precipitation anomalies for El Niño events classified as DF+ (left panels) and DF- (right panels) for the 3-month period November-January (a) and (b) during the El Niño peak; and April-June (c) and (d) during the year following the El Niño onset. Anomalies are relative to the 1950-2000 base period. Contours are shown for $\pm 5, \pm 15, \pm 30$ then each $\pm 10 \mathrm{~cm} \mathrm{month}^{-1}$. Dashed contours indicate negative anomalies. Shading in green (brown) indicates positive (negative) anomalies at the 95\% confidence level according to Student's $t$-test; darker shading at the $99,99.5$ and $99.9 \%$ level. This figure is available in colour online at www.interscience.wiley.com/ijoc

Shadows denoting statistical significance in Figure 6(a) and (b) are shifted from the location of the precipitation anomaly cores during both types of El Niño events. This may be due to the high spatial variability of precipitation during $\operatorname{NDJ}(0)$ between individual El Niño events (Ropelewski and Halpert, 1987; Grimm et al., 2000).

During $\mathrm{AMJ}(+)$, positive anomalies of $\mathrm{DF}+$ events (Figure 6(c)) become stronger, as they move northeastward to be centred at $25^{\circ} \mathrm{S} 54^{\circ} \mathrm{W}$. The statistically significant anomaly core exceeds $300 \mathrm{~mm}$ and is located over the upper Paraná basin. These precipitation anomalies cause major floods downstream in the Paraná River (Camilloni and Barros, 2003). On the other hand, during DF- events (Figure 6(d)) the same area is covered by negative precipitation anomalies. In particular, there is a well-defined negative core lower than $100 \mathrm{~mm}$ centred at $27^{\circ} \mathrm{S} 56^{\circ} \mathrm{W}$. The affected area covers the middle Paraguay basin, thus causing low river discharges during this season.

Despite the relationship between the type of El Niño event and autumn precipitation anomalies, it is evident in Table I that most of the DF+ events occurred after the 1970s. In this way, recent findings of Andreoli and Kayano (2005) and Kayano and Andreoli (2006, 2007) relate to precipitation anomalies in South America with the phases of the PDO and the phases of ENSO. When both oscillations are in (out of) phase, precipitation anomalies are stronger (weaker) than usual for a given season, as observed during $\operatorname{AMJ}(+)$.

\section{El Niño 1997-1998}

Even though this event has not been classified as DF+, the sea surface temperature remains very high in the tropical Pacific during April-June 1998 (Figure 7(a)). The maximum in the Niño $1+2$ anomaly series occurs in November 1997, but a secondary maximum in April 1998 resembles the absolute maximum typical of DF+ events (see Figure 2(f)). In response to the warming on the eastern tropical Pacific, the anticyclonic anomalies pair dominates circulation at high levels centred off the equator (Figure 7(b)). This causes an eastward extension of the South Pacific subtropical jet stream. At low levels, positive humidity advection anomalies occur at $20^{\circ} \mathrm{S}$ $60^{\circ} \mathrm{W}$ within an anomalous northwesterly flow along the eastern slopes of the Andes (Figure 7(c)). Consequently, a surplus of humidity convergence may be favoured upstream of the area where a positive precipitation anomaly is observed, with some localized values above $400 \mathrm{~mm}$ to the north of Uruguay (Figure 7(d)). Monthby-month analysis of precipitation anomalies (not shown) reveals that most of the April-June 1998 precipitation occurs during April. This is not surprising since at the end of the 1997-1998 El Niño, a sudden cooling develops in the central Pacific after April 1998, as it was shown by the Niño 3.4 anomaly index in Figure 2(f). Then, the positive precipitation anomaly core in Figure 7(d) during April-June is affected by the spatial distribution of April precipitation totals and results in a southward shift 

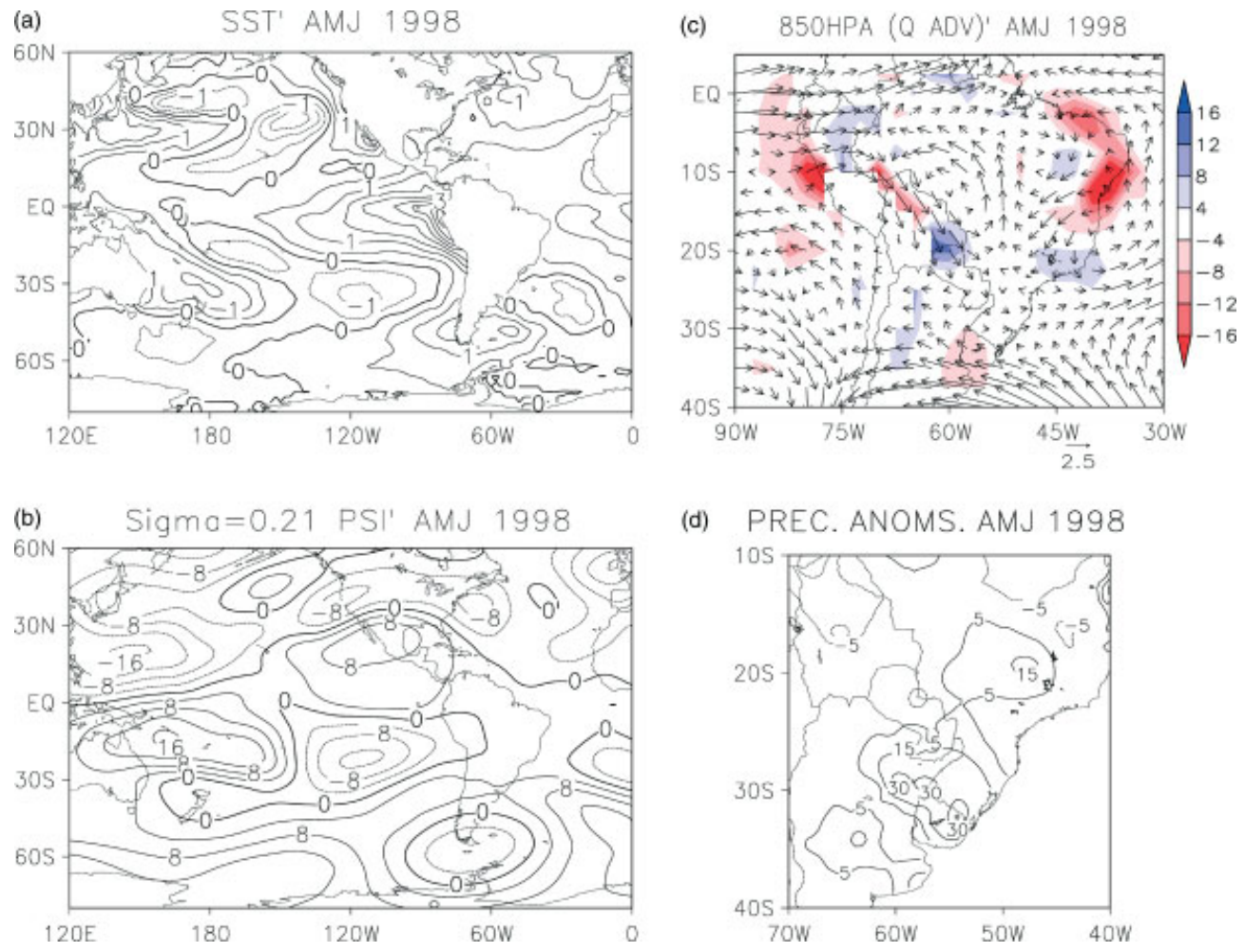

(d)

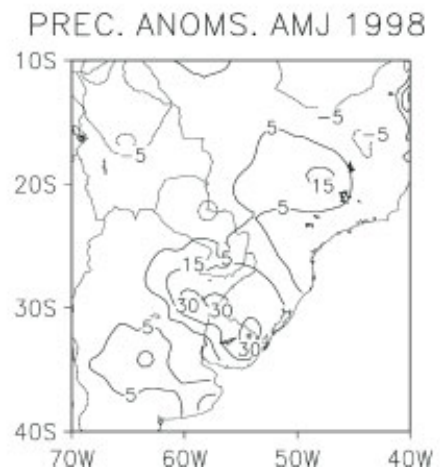

Figure 7. Mean anomaly fields for the 3-month period April-June 1998 of: (a) sea surface temperature, (b) stream-function at the 0.21-sigma level, (c) wind and specific humidity advection at the 850 -hPa level, and (d) 3-month precipitation. Contours each $0.5^{\circ} \mathrm{C}, 4 \times 10^{6} \mathrm{~m}^{2} \mathrm{~s}^{-1}$, $4 \times 10^{-3} \mathrm{~g} \mathrm{~kg}^{-1} \mathrm{~s}^{-1}$, and 5, 15, 30 then each $10 \mathrm{~cm} \mathrm{month}^{-1}$. Dashed contours indicate negative values. Reference vector in (c) is $2.5 \mathrm{~m} \mathrm{~s}$.

Anomalies are relative to the base period 1950-2000. This figure is available in colour online at www.interscience.wiley.com/ijoc

compared with the DF+ events precipitation anomaly composite (Figure 6(c)).

\section{Summary and conclusions}

The classification of El Niño events is based on the phase lag between the time series of the Niño 3.4 and Niño $1+2$ indices during the 1950-2000 period. Thus, two sets of DF+ and DF- events were respectively built with their corresponding anomaly composites. In the first type $(\mathrm{DF}+)$ positive sea surface temperatures maximize in the eastern tropical Pacific during $\operatorname{AMJ}(+)$, whereas in the second type (DF-) the latter occurs immediately after the El Niño onset during $\mathrm{MJJ}(0)$. In addition, the first type has associated higher than normal precipitation totals over southeastern South America during $\mathrm{AMJ}(+)$. The analysis of the anomaly composites revealed there is a favourable combination of upperlevel cyclonic vorticity advection and low-level humidity convergence in the region. An anomalous high-level low at $35^{\circ} \mathrm{S}$ is centred off the South American coast over the Pacific Ocean. Together with an anomalous highlevel anticyclone on the eastern tropical South Pacific, it produces an eastward extension of the subtropical jet that favours cyclonic vorticity advection over South America. Simultaneously, there is an enhancement of humidity advection by the low-level northwesterly flow east of the Andes. This advection increases moisture availability over an area that encompasses the upper Paraná basin.
The similarity is remarkable between this anomalous pattern of low-level circulation and that described by Nicolini et al. (2002) for the occurrence of low-level jets characterized by their extension farther south in subtropical South America during summer. That paper relates to jet episodes with major precipitation events in our study region. Thus, the described high- and low-level circulation patterns for DF+ events combine together to produce more precipitation than usual during $\mathrm{AMJ}(+)$. On the other hand, during $\mathrm{AMJ}(+)$ after the $\mathrm{DF}-$ events there are no major anomalies both in precipitation and circulation patterns. Thus, this type of events is related with near-average or slightly below average rainfall totals in southeastern South America.

There are a number of El Niño events during the 1950-2000 period that cannot be classified into DF+ or DF- events. One of them is the El Niño 1997-1998, which was the strongest warm event ever recorded in the Pacific Ocean. During this event, the persistence of extremely high sea surface temperature anomalies in the eastern tropical Pacific is accompanied by anomalous circulation patterns quite similar to those of the DF+ events. Therefore, major precipitation anomalies occur in southeastern South America during April-June 1998.

The occurrence of a given type of event is not even along the analysed period. In fact, most of the DF+ events occur after the 1970s, DF- events occur before. These results are in concordance with those of Wang (1995) who found changes in the onset of El Niño 
episodes before and after the late 1970s, when an abrupt interdecadal change is observed from cold to warm conditions in the Pacific Ocean. In fact, the anomaly composites of sea surface temperature for $\mathrm{DF}+$ events resemble the warm phase pattern of the PDO, which changed its phase during the 1970s (Mantua et al., 1997). It consists of positive anomalies along the equatorial Pacific, and negative anomalies in the subtropical southcentral Pacific (as shown in Figure 3(e)). A similar pattern was found by Barros and Silvestri (2002) for El Niño events with major precipitation anomalies in subtropical South America during spring $(0)$. They emphasized the role of negative sea surface temperature anomalies in the subtropical southcentral Pacific during El Niño. The background defined by the PDO warm phase strengthens the El Niño impacts on precipitation in southeastern South America during autumn(+) (Andreoli and Kayano, 2005; Kayano and Andreoli, 2006, 2007). Therefore, low-frequency processes such as those related to the PDO may be the ones that modulate the evolution of each El Niño event.

The method applied to classify El Niño events is based on monthly values of sea surface temperature indices. Considering that the Niño $1+2$ index maximizes before $\operatorname{July}(0)$ in the case of DF- events, it is possible to classify an ongoing El Niño event at the time the Niño 3.4 maximum occurs, i.e. during January $(+)$ or before. Furthermore, the type of event is closely related with autumn $(+)$ precipitation anomalies. In particular, the high rainfall totals observed during $\mathrm{DF}+$ events may cause severe flooding (Camilloni and Barros, 2003). Therefore, the methodology used may also be regarded as a potential contribution to the monitoring of regional climate.

\section{Acknowledgements}

The author thanks V. Barros and two anonymous reviewers for their useful comments on the manuscript. This research is sponsored by Agencia Nacional de Promoción Científica y Tecnológica through Grant PICT BID 1728 OC-AR 14202.

\section{References}

Aceituno P. 1988. On the functioning of the Southern Oscillation in the South American sector. Part I: surface climate. Monthly Weather Review 116: 505-524.

Andreoli RV, Kayano MT. 2005. ENSO-related rainfall anomalies in South America and associated circulation features during warm and cold Pacific Decadal Oscillation regimes. International Journal of Climatology 25: 2017-2030.

Antico PL. 2003. Occurrence of extreme events in the monthly mean subtropical jet intensity over South America during winter (T). $\mathrm{PhD}$ dissertation. University of Buenos Aires, Buenos Aires.

Barros VB, Chamorro L, Coronel G, Baez J. 2004. The major discharge events in the Paraguay River: magnitudes, source regions, and climate forcings. Journal of Hydrometeorology 5: 1161-1170.

Barros VB, Silvestri GE. 2002. The relation between sea surface temperature at the subtropical South-central Pacific and precipitation in Southeastern South America. Journal of Climate 15: 251-267.

Berri GJ, Ghietto MA, García NO. 2002. The influence of ENSO in the flows of the Upper Paraná River of South America over the past 100 years. Journal of Hydrology 3: 57-65.

Camilloni IA, Barros VR. 2003. Extreme discharge events in the Paraná River and their climate forcing. Journal of Hydrology 278: 94-106

Diaz AF, Studzinski CD, Mechoso CR. 1998. Relationships between precipitation anomalies in Uruguay and Southern Brazil and sea surface temperature in the Pacific and Atlantic Oceans. Journal of Climate 11: $251-271$.

Grimm AM, Barros VR, Doyle ME. 2000. Climate variability in Southern South America associated with El Niño and La Niña events. Journal of Climate 13: 35-58.

Grimm AM, Ferraz SET, Gomes J. 1998. Precipitation anomalies in Southern Brazil associated with El Niño and La niña events. Journal of Climate 11: 2863-2880.

Kalnay E, Kanamitsu M, Kistler R, Collins W, et al. 1996. The NCEP/NCAR 40-year reanalysis project. Bulletin of the American Meteorological Society 77: 437-471.

Kayano MT, Andreoli RV. 2006. Variabilidad en baja frecuencia. In $\mathrm{El}$ Cambio Climático en la Cuenca del Plata, Barros V, Clarke R, Silva Dias P (eds). CONICET: Buenos Aires.

Kayano MT, Andreoli RV. 2007. Relations of South American summer rainfall interannual variations with the Pacific Decadal Oscillation. International Journal of Climatology 27: 531-540.

Legates DR, Willmott CJ. 1990. Mean seasonal and spatial variability in gauge-corrected, global precipitation. International Journal of Climatology 10: 111-127.

Mantua NJ, Hare SR, Zhang Y, Wallace JM, Francis RC. 1997. A Pacific interdecadal climate oscillation with impacts on salmon production. Bulletin of the American Meteorological Society 78: 1069-1079.

Nicolini M, Saulo AC, Torres JC, Salio P. 2002. Enhanced precipitation over Southeastern South America related to strong low-level jet events during austral warm season. Meteorological 27: 59-69.

Rasmusson EM, Carpenter TH. 1982. Variations in tropical sea surface temperature and surface wind fields associated with the Southern Oscillation/El Niño. Monthly Weather Review 110: 354-384.

Ropelewski CF, Halpert MS. 1987. Global and regional scale precipitation patterns associated with the El Niño/Southern Oscillation. Monthly Weather Review 115: 1606-1626.

Smith TM, Reynolds RW. 2004. Extended reconstruction of global sea surface temperatures based on COADS data (1854-1997). Journal of Climate 16: 1495-1510.

Trenberth KE. 1997. The definition of El Niño. Bulletin of the American Meteorological Society 78: 2771-2777.

Wang B. 1995. Interdecadal changes in El Niño onset in the last four decades. Journal of Climate 8: 267-285.

Wang XL, Ropelewski CF. 1995. An assessment of ENSO-Scale secular variability. Journal of Climate 8: 1584-1599. 